\title{
METODOLOGIA PARA CRIAÇÃO DE UM BANCO DE DADOS GEOREFERENCIADO A PARTIR DE DADOS GEOTÉCNICOS OBTIDOS EM "AS BUILT" E PROJETOS RODOVIÁRIOS
}

\section{Methodology for creation of a georeferenced database from geotechnical data obtained in "as built" and road projects}

\author{
Antonio Júnior Alves Ribeiro', Carlos Augusto Uchôa da Silva², Suelly Helena de Araújo Barroso ${ }^{3}$
}

Recebido em 14 de janeiro de 2016; recebido para revisão em 23 de março de 2016; aceito em 08 de maio de 2016; disponível on-line em 04 de julho de 2016.

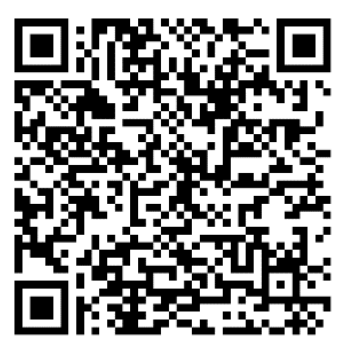

PALAVRAS CHAVE:

SIG;

Banco de Dados

Geotécnicos;

Pavimentação;

Geoprocessamento;

Solos.

\section{KEYWORDS:}

GIS;

Geotechnical Database;

Paving;

Geoprecessing;

Sails.

\footnotetext{
* Contato com os autores:

${ }^{1}$ e-mail: ajar.junior@gmail.com (A. J. A. Ribeiro)

2e-mail: uchoa@det.ufc.br (C. A. U.da Silva)

Professor Doutor da Universidade Federal do Ceará - UFC.

${ }^{3}$ e-mail: suelly@det.ufc.br (S. H. A. Barroso)

Professora Doutora da Universidade Federal do Ceará - UFC.
}

Doutorando do Programa de Pós-Graduação em Eng. de Transportes (PETRAN-UFC), Professor do Instituto Federal do Ceará - IFCE.
ABSTRACT: This article proposes a methodology for generation and implementation of a spatial digital database, that makes it easier to store, view and query information and parameters of physical, biotic and anthropic environment of interest to the pavement. The aim of this research objective is to design an efficient and easy replication method, to extract geotechnical information from road projects already built, and enter this information in the database to aid in early recognition of the geotechnical characteristics of the sub grade occurring in a region. A feature of the proposed database is the ability to connect to Geographic Information Systems (GIS), from the introduction of the spatial information of the stored parameters, this feature enables the integration of geotechnical data to infrastructure, anthropogenic, biophysical georeferenced information. The results were significant, considering the generation of thematic maps and spatial analysis, supported by geotechnical database created. 


\section{INTRODUÇÃO}

\subsection{CONTEXTUALIZAÇÃO DA PROBLEMÁTICA}

O crescimento das cidades brasileiras tem demandado uma grande expansão da malha viária, tornando-se indispensável o conhecimento e mapeamento dos materiais com potencial emprego nas obras de infraestrutura e principalmente no âmbito da pavimentação. Na área rodoviária, o conhecimento das características do subleito, das jazidas e de empréstimos de solos são condicionantes que influenciam diretamente $o$ projeto e os custos de qualquer obra. Esse fato leva os projetistas a buscarem, preferencialmente, explorar os materiais que estiverem localizados o mais próximo possível da obra a que estes se destinam.

$\mathrm{Na}$ engenharia geotécnica, as características de textura são utilizadas para classificar os solos qualitativamente para o uso em pavimentação rodoviária ou engenharia em geral. $\mathrm{Na}$ área rodoviária é comum a adoção de um sistema de classificação de solos para prever as suas propriedades. A classificação AASHTO tem sido a mais utilizada para esse fim, embora existam outros métodos também consagrados no Brasil, como a classificação MCT (Miniatura, Compactado, Tropical). Essa última classificação foi desenvolvida por Nogami e Villibor (1981) para identificar o comportamento laterítico de solos brasileiros que não consegue ser previsto adequadamente na classificação AASHTO.

Para projetos de pavimentos, é essencial se conhecer o comportamento dos solos quando submetidos ao carregamento do tráfego local, sendo o CBR (Califórnia Bearing Ratio) e o MR (Módulo de Resiliência), os parâmetros mais importantes a serem determinados quando o dimensionamento é empírico ou mecanísticoempírico, respectivamente. Esses parâmetros podem ser obtidos nos relatórios dos estudos geotécnicos que compreendem os estudos do subleito e das ocorrências de materiais para pavimentação.

As classificações e valores de resistência dos solos são obtidos através de sondagens e ensaios de laboratório que demandam gasto de grande tempo e recursos financeiros. Os dados resultantes dos estudos geotécnicos de obras rodoviárias ficam geralmente armazenados em relatórios internos dos órgãos rodoviários e empresas de Geotecnia. Considera-se que tais informações são preciosas e que se fossem mais bem organizadas poderiam compor um banco de dados geotécnico que retratasse a realidade dos tipos de materiais ocorrentes em uma dada região.

Adicionalmente, percebe-se que nos projetos rodoviários do estado do Ceará realizados até 2015, nem o DNIT (Departamento Nacional de Infraestrutura de Transportes) e nem o DER/CE (Departamento de Edificações e Rodovias do Ceará) executam georreferenciamento dos locais de sondagens. Assim, as posições desses locais ficam relacionadas apenas às estacas do eixo diretriz das rodovias, fato este que pode acabar levando ao retrabalho para futuros usos de materiais da mesma região onde já são conhecidos os solos locais. Esse tipo de problema pode ser mitigado com a implementação e população de um banco de dados georreferenciado com tais informações.

Uma metodologia para mapeamento geotécnico foi desenvolvida e publicada por Dias (1995), na qual se utilizam ferramentas cartográficas e de Geoprocessamento para definição de unidades geotécnicas. Esse mapeamento foi realizado a partir do cruzamento de informações pedológicas e geológicas que resultaram na idealização de perfis de solos com provável comportamento geotécnico similar. $\mathrm{O}$ uso do Geoprocessamento possibilitou a agregação das informações mapeadas a um banco de dados, de tal modo que esses dados possam ser utilizados de forma centralizada e integrados a outras características do meio físico.

Neste contexto, esta pesquisa propõe a utilização de ferramentas de Geoprocessamento, mais especificamente um Sistema de Informações Geográficas (SIG) para a geração de um banco de dados georreferenciado de informações geotécnicas para o município de Caucaia/CE. Para tanto, serão utilizadas informações pré-existentes de projetos rodoviários, onde os dados não estão georreferenciados, buscando a estruturação de cartas e banco de dados que identifiquem as 
propriedades apresentadas pelos solos do município no que tange à sua potencial aplicação em obras de pavimentação. $O$ banco de informações proposto permitirá, ainda, a agregação de outras informações do meio físico (clima, relevo, vegetação, hidrografia, geologia, pedologia, etc.) no qual está inserido, permitindo a geração de outros tipos de cartas e a análise espacial dos fenômenos relacionando a Geotecnia com fatores biofísicos e/ou antrópicos.

\subsection{SISTEMAS DE INFORMAÇÕES GEOGRÁFICAS}

Os SIGs foram concebidos para inserir e integrar, em uma única base de dados, informações espaciais provenientes de meio físico-biótico, de dados censitários, de cadastros urbano e rural, e outras fontes de dados como imagens de satélite, e dos sistemas GNSS (Global Navigation Satellite System). O SIG é capaz de oferecer mecanismos para combinar as várias informações, por meio de algoritmos de manipulação e análise, bem como para consultar, recuperar e visualizar o conteúdo da base de dados geográficos. A Figura 1 ilustra os componentes de um SIG.

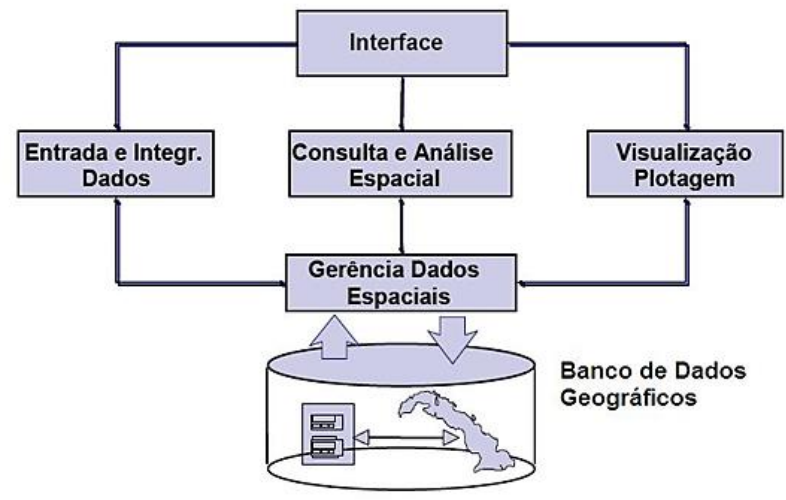

FIGURA 1: Componentes de um SIG.

FONTE: adaptado de Câmara et al., (1996).

Entende-se como Sistema de Informação Geográfica (SIG) um conjunto de ferramentas que permite análise, envolvendo dados espaciais e não espaciais sobre o espaço terrestre. Um SIG permite a associação de dados geográficos a uma infinidade de atributos (dados alfanuméricos), possibilitando assim a realização de consultas, análises e simulações, envolvendo todo tipo de informação onde a variável 'espaço' seja particularmente importante (Almeida, 2000).
De acordo com Câmara et al. (1996), o termo SIG é aplicado para sistemas que realizam o tratamento computacional de dados geográficos. A principal diferença de um SIG para um sistema de informação convencional é sua capacidade de armazenar tanto os atributos descritivos, como as geometrias dos diferentes tipos de dados geográficos. Assim, para cada furo (ponto) em um cadastro de sondagens, por exemplo, um SIG pode armazenar, além de informações descritivas como numeração do furo de sondagem, endereço e perfil geotécnico, também a informação espacial a partir de suas coordenadas.

Pode-se considerar o SIG como um conjunto de ferramentas para coleta, armazenamento e recuperação de dados espaciais (Burrough, 1986), ou também, como um conjunto de procedimentos, manual ou informatizado, utilizado para armazenar e tratar dados geograficamente referenciados (Aronoff, 1989). Segundo Fortes (1998), a ênfase no dado geográfico é o que diferencia o SIG de outros sistemas computacionais. Os dados em SIG são armazenados em uma base de dados, denominada banco de dados geográficos.

Os primeiros Sistemas de Informações Geográficas não foram projetados para dar suporte a dados alfanuméricos. Eles foram desenvolvidos para prover análise espacial, visualização cartográfica, não dando tanta importância em oferecer recursos de banco de dados (Reeve, 2001). A necessidade de integração de dados espaciais com dados convencionais foi uma preocupação posterior ao desenvolvimento das ferramentas SIG.

A essa necessidade deve-se a existência de informações alfanuméricas que precisavam ser integradas as informações espacializadas, nascendo assim à arquitetura de bancos de dados geográficos. Essa integração é importante, senão fundamental, porque permite a análise conjunta de vários tipos de informações e onde elas ocorrem no espaço (Silva, 2002). Ainda possibilita à expansão e agregação de novas informações posterior a criação da base de dados.

Câmara e Queiroz (2006) afirmam que a construção de uma base com informações e dados 
geográficos é um processo demorado e trabalhoso, onde se gasta a maior parte dos recursos.

Os SIGs são bastante utilizados em diversas áreas da ciência e engenharia, tendo sido empregados em trabalhos que envolvem variáveis biofísicas e fenômenos especializados, onde se deseja entender melhor os processos a distribuição de ocorrência de fenômenos. Nas áreas da ciência e engenharia que tem como objeto de estudo os solos os SIGs estão tendo bastante aplicabilidade e desenvolvimento.

O mapeamento digital de solos tem como base os sistemas de informação geográfica e estatística, essa técnica está aumentando nas últimas décadas em razão do aumento de fontes de dados numéricos, incorporados aos SIGs como aqueles fornecidos pelos modelos digitais de elevação da superfície do solo (MDE), combinado com o desenvolvimento de novas ferramentas de processamento de informação (McBratney et al., 2003).

Ribeiro et al., (2015) utilizaram SIG e Redes Neurais Artificiais para realizar o mapeamento dos solos da Região Metropolitana de Fortaleza pela Classificação de Solos da AASHTO. O SIG utilizado na pesquisa foi ArcGIS 9.3, que foi usado para fazer a extrapolação dos resultados dos modelos neurais, criação do banco de dados e confecção dos mapas.

Rovani e Vieira (2016), estudaram a vulnerabilidade natural dos solos do município de Silveira Martins-RS, nesse processo o SIG foi muito importante, pois possibilitou construir e manipular o banco de dados de informações/variáveis para criar o modelo de vulnerabilidade do solo espacializado.

\subsection{OBJETIVO}

Esta investigação tem como objetivo principal o desenvolvimento e aplicação de uma metodologia, baseada em Geoprocessamento, para criação de um banco de dados geotécnico georreferenciado. Esse banco de dados será obtido a partir de estudos, projetos e "as built" de obras rodoviárias, cujos dados não se encontrem georreferenciados. Especificamente espera-se que o banco de dados, através de SIGs, conecte os dados geotécnicos a outras informações do meio físico estudado e assim difundir o emprego da metodologia aqui adotada.

\section{MATERIAIS E MÉTODOS}

\subsection{CARACTERIZAÇÃO DA ÁREA DE ESTUDO}

O município de Caucaia está localizado na Região Metropolitana de Fortaleza (RMF), no estado do Ceará, com latitude $3^{\circ} 44^{\prime} 10^{\prime \prime} \mathrm{S}$ e longitude $38^{\circ} 39^{\prime} 11^{\prime \prime} \mathrm{W}$. Esse município ocupa uma área de $1.223,796 \mathrm{~km}^{2}$, distando cerca de $15 \mathrm{~km}$ da capital do Ceará, tendo população estimada em 325.441habitantes (IBGE, 2010).

A cidade de Caucaia está delimitada ao norte pelo oceano Atlântico; ao sul, pelo município de Maranguape; a leste, pelos municípios de Fortaleza, Maranguape e Maracanaú; a oeste, pelos municípios de São Gonçalo do Amarante e Pentecoste. A Figura 2 traz a localização de Caucaia na RMF, no Ceará e no Brasil.

Caucaia é o maior município em extensão territorial dentre os que integram a RMF, ocupando cerca de $24 \%$ de sua área total e possui a segunda maior população do estado do Ceará, sendo que nele está inserido o Complexo Industrial e Portuário do Pecém (CIPP), nos limites de São Gonçalo do Amarante e Caucaia. Possui ainda, uma malha viária constituída por cinco rodovias de grande porte, duas federais e três estaduais, são elas: BR-222, BR-020, CE-085, CE-090 e a CE-348. A Figura 3 destaca a malha rodoviária pavimentada de Caucaia.

Desde a inauguração do Porto do Pecém, em 2002, no município de São Gonçalo do Amarante (SGA) e do CIPP (Complexo Industrial e Portuário do Pecém) em SGA e Caucaia, muitos investimentos industriais tem se deslocado para região. A Refinaria Premium II da Petrobrás, a Companhia Siderúrgica do Pecém, a Termelétrica Porto do Pecém Geração de Energia são exemplos de novas indústrias que somam investimentos de cerca de US\$ 22.100.000.000,00. (IPECE, 2010).

Para que esses empreendimentos tornem-se viáveis, o poder público investirá na melhoria da infraestrutura da região, tendo como principais focos: duplicação e desvios de rodovias existentes e abertura de novas rodovias, além de melhoria das vias já implantadas. Esses 
investimentos devem trazer grande demanda de estudos de solos na região para fins de pavimentação e uso em Engenharia no geral.

Alguns trabalhos de reconhecimento de solos para fins de pavimentação já foram executados na RMF, pode-se citar os trabalhos de Barroso (2002) e Chaves (2000). Sendo que o primeiro realizou a caracterização de sessenta solos, dos quais $28 \%$ das amostras foram coletadas no município de Caucaia. Essas amostras foram georreferenciadas com o auxílio do sistema GPS (Global Positioning System), possibilitando a obtenção de suas coordenadas geográficas, viabilizando assim, o futuro emprego desses dados em ambiente SIG. Já o segundo caracterizou geotecnicamente a Formação Barreiras da região segundo a metodologia MCT.

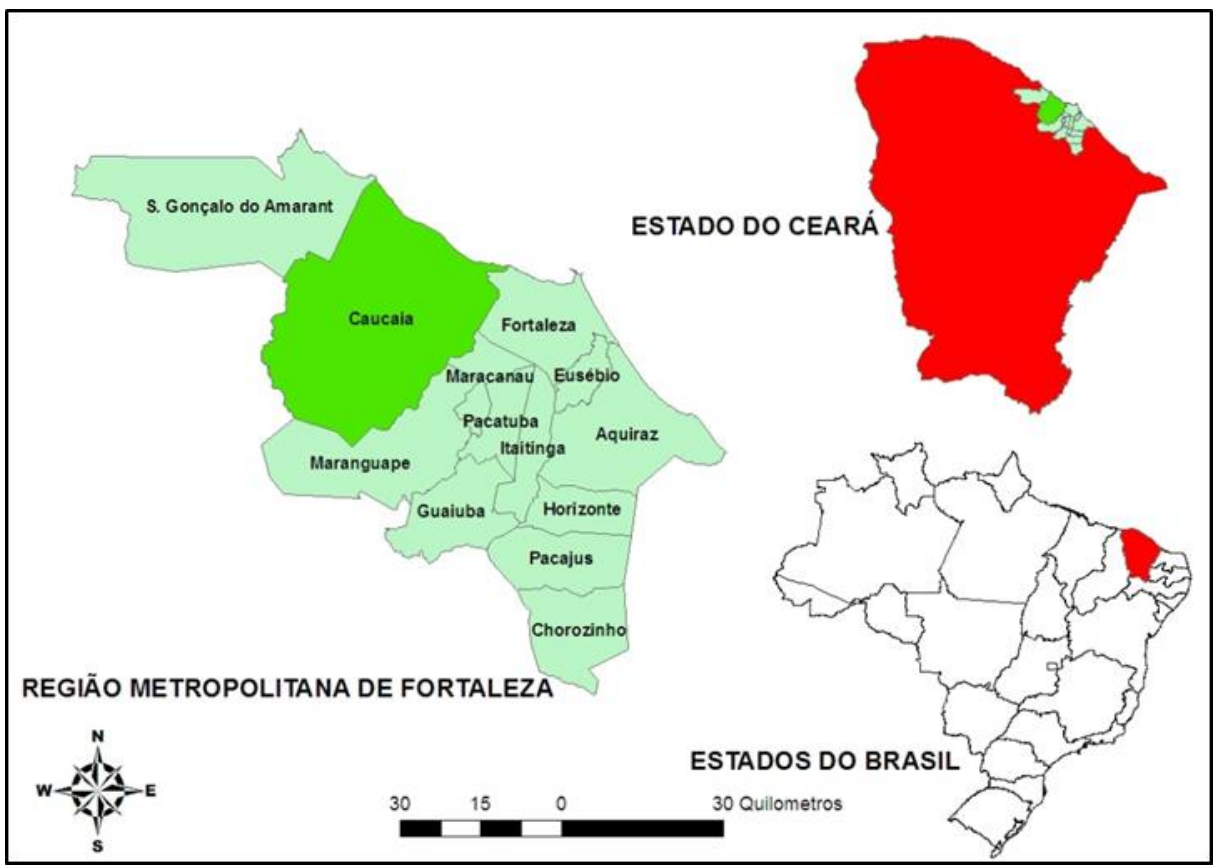

FIGURA 2: Localização do Município de Caucaia. FONTE: Autoria Própria.

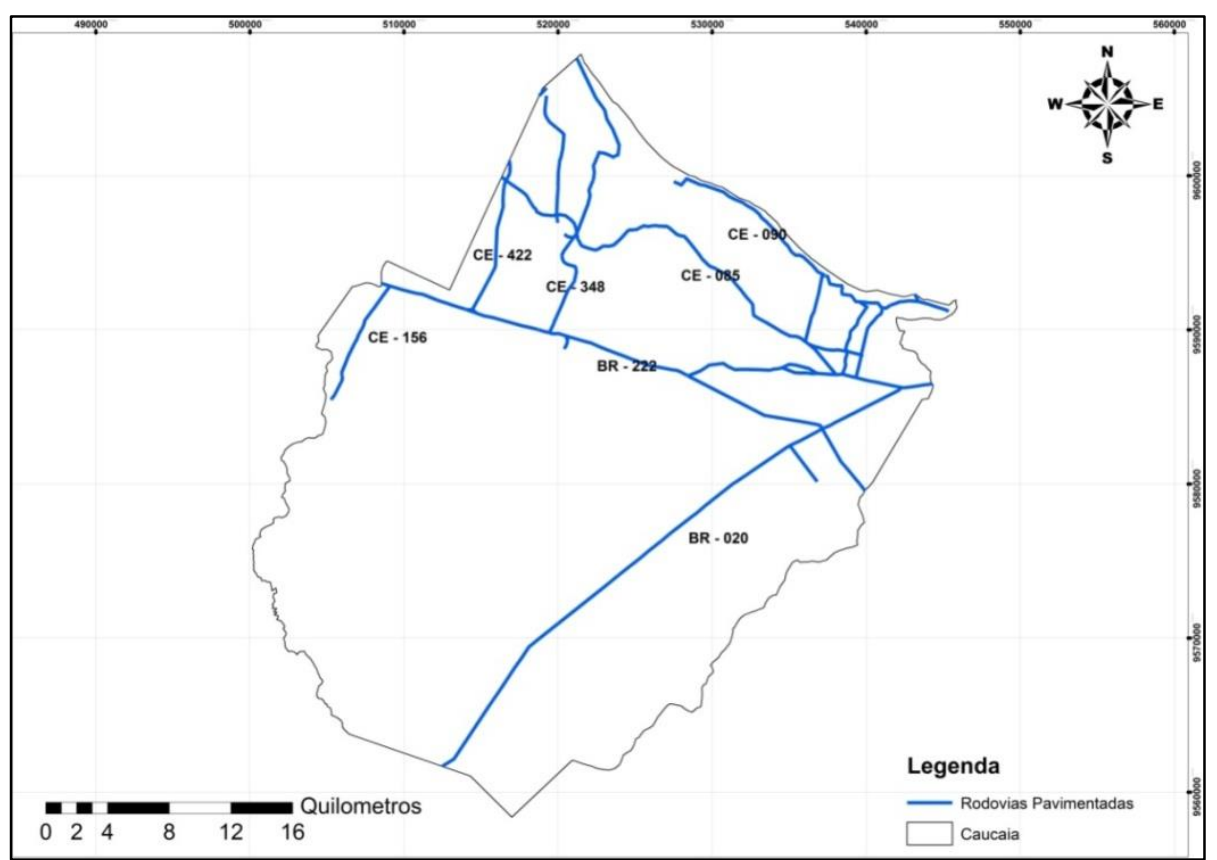

FIGURA 3: Malha Rodoviária Pavimentada de Caucaia. FONTE: Autoria Própria. 


\subsection{DADOS E SOFTWARES}

Para se chegar aos objetivos propostos por este trabalho, utilizaram-se softwares de Geoprocessamento e análise espacial, bem como dados secundários espacializados e não espacializados do meio físico/antrópico e de projetos rodoviários. Os aplicativos computacionais utilizados nessa proposta metodológica foram o ArcGIS e o AutoCad Civil 3D. Esses aplicativos foram desenvolvidos, respectivamente, pela ESRI e pela Autodesk para executar todas as operações espaciais de georreferenciamento, integração do banco com outras informações, produção de mapas, dentre outras. Já o Microsoft Access foi utilizado para criar e popular o banco de dados para posterior agregação da posição geográfica.

Os dados secundários utilizados nesta investigação foram obtidos junto aos órgãos públicos que detinham as informações necessárias, tais como: O IPECE (Instituto de Pesquisas Econômicas do Ceará), o DER/CE e o DNIT.

\subsection{CONSTRUÇÃO DA BASE DE DADOS}

Para construção da base de dados buscouse os dados julgados importantes para o georreferenciamento dos pontos geotécnicos, bem como as operações espaciais necessárias à construir o banco de dados.

Os dados espaciais obtidos foram manipulados de acordo com o formato adquirido, tal manipulação precisou ser realizada para promover uma uniformização, ou seja, que todos os dados tivessem o mesmo formato, mesmo sistema de coordenadas, mesmo sistema de referência e restritos à área de estudo, neste caso, o limite do município de Caucaia-CE.

Com isso foi possível diminuir para área de estudos todas bases de dados adquiridas junto a IPECE, DER/CE e DNIT.

\subsection{GEORREFERENCIAMENTO DA BASE DE DADOS}

Nesta etapa buscou-se técnicas de geoprocessamento para especializar as sondagens geotécnicas realizadas durantes os projetos e "as built" das rodovias. Os pontos relativos à coleta de dados geotécnicos nesse estudo foram divididos em três categorias: sondagens do subleito, sondagens de empréstimos e sondagens de jazidas, adquiridos em formato analógico e não georreferenciados.

Esses pontos foram locados em relação ao estaqueamento do eixo diretriz da estrada, sendo os dados de subleito localizados sobre o eixo e bordas e os das jazidas e empréstimos localizados com distâncias sempre perpendiculares ao eixo da via. É esse procedimento, descrito nos estudos geotécnicos, que torna possível a extração das coordenadas geográficas dos locais amostrados, ou seja, a partir do formato em que se encontram os dados, torna-se possível fazer a espacialização dos mesmos.

\section{RESULTADOS}

\subsection{METODOLOGIA DA PROPOSTA}

\subsubsection{Aquisição dos Dados}

Para obtenção dos dados necessários foram realizadas visitas aos órgãos já citados e consultas via web. Os dados essenciais, tais como: Base Territorial Nacional, Base Territorial Estadual e Base Territorial Municipal, foram levantadas junto ao IPECE. No DER/CE levantou-se a Base das Rodovias no estado do Ceará. Já no DNIT, conseguiu-se o projeto de duplicação da BR-222 de um trecho de $30 \mathrm{~km}$, que cruza a RMF e consequentemente o município de Caucaia, contendo os estudos geotécnicos.

\subsubsection{Manipulando os Dados}

Os dados obtidos junto ao IPECE e DER/CE foram em meio digital e formato vetorial (shapefile) e estavam georreferenciados ao datum horizontal SAD69 (South American Datum 1969). Inicialmente, para promover uma compatibilização e uniformização entre sistemas de referência e sistemas de coordenadas, os dados tiveram o seu sistema de coordenadas modificado para SIRGAS2000, com sistema de projeção cartográfica UTM (Universal Transverso de Mercator), Fuso UTM 24 Sul. Após isso, as bases passaram por um processo de recorte através da operação "clip" no ArcGIS, com o objetivo de reduzir as bases 
territoriais e rodoviárias aos limites da área estudada.

O projeto da duplicação da BR-222 foi obtido em meio analógico, formato impresso, bem como os estudos geotécnicos referentes a esse projeto. Iniciou-se então a digitalização dos dados referentes aos resultados dos ensaios de laboratório, do trecho investigado de $30 \mathrm{~km}$, usando-se o aplicativo Access para gerar um banco de dados tabular. Assim, para cada ponto estudado foi criada uma linha e três colunas, sendo que a primeira coluna recebeu um identificador numérico auto-incrementável para servir de chave primária para posterior georreferenciamento deste banco de dados. A segunda coluna teve a informação AASHTO adicionada. Inseriu-se a informação do CBR na terceira coluna criada. Esse procedimento gerou como resultado o banco de dados com as informações geotécnicas das sondagens do projeto da BR-222. A Figura 4 apresenta a manipulação de dados sendo executado no ArcGIS 9.3.

\subsubsection{Geoprocessamendo os Dados}

Para se realizar a operação de georreferenciamento dos dados analógicos foi utilizada a inserção de pontos com coordenadas relativas ao eixo estradal a partir do software Autodesk Civil 3D (Ver Figura 5). Esse procedimento foi realizado da seguinte forma:

a) Configuração do Civil 3D para receber dados no datum SIRGAS2000 e sistema de projeção cartográfica UTM, Fuso 24 Sul;

b) Importação da Base de Rodovias e da Base Territorial de Caucaia, para o Civil 3D, utilizadas para localização dos pontos geotécnicos junto ao eixo da BR-222 de forma mais precisa possível;

c) Estaqueamento da linha da rodovia a cada 200 metros, a partir do ponto inicial do trecho em estudo, obtendo-se, assim, a localização exata dos pontos sondados no subleito, quer seja no eixo ou nas bordas. Observe-se que o estudo seguiu o Manual de Pavimentação do DNIT (2006) que recomenda que, em média, a cada 200 metros seja realizada uma sondagem de reconhecimento do subleito da rodovia; d) Inserção de um ponto no formato vetorial em cada localização de sondagem obtida conforme descrito no item $c$;

e) Para localização dos pontos referentes aos empréstimos e jazidas, foram criadas linhas perpendiculares ao eixo da BR-222 com a distância exata que separa a estaca de referência da sondagem e o local onde foi coletado o material de cada empréstimo e jazida, sendo que ao final de cada linha estava a localização geográfica dos pontos estudados;

f) Inserção de pontos em formato vetorial nos locais onde se encontravam as jazidas e empréstimos conforme localizados como explicado no item anterior $d$. Neste procedimento, teve-se o cuidado de atribuir um número a cada ponto inserido fazendo com que cada número correspondesse ao índice das informações geotécnicas do mesmo. No banco de dados criado, esse procedimento foi desenvolvido para viabilizar a agregação de coordenadas a esse banco;

g) Conversão e exportação dos pontos criados no Civil 3D que inicialmente estavam em vetorial (.dwg) para o formato shapefile (.shp), para que possam ser lidos em ambiente SIG.

Após a manipulação dos dados e georreferenciamento dos locais de sondagem, tornou-se possível à integração dos pontos às informações geotécnicas dos mesmos, consolidando, assim, um banco de dados georreferenciado (ver Figura 6). Tal operação foi concebida utilizando 0 software de Geoprocessamento ArcGIS 9.3, da seguinte forma:

i) Configuração do ArcGIS para receber dados no sistema SIRGAS2000, em sistema de projeção cartográfica UTM, Fuso 24 Sul;

ii) Inserção dos pontos criados a partir do Autocad Civil 3D. Além das bases territoriais e rodoviárias do município de Caucaia, ainda foi inserido o banco de dados criado, agrupando todos os dados na mesma plataforma operacional; 
iii) Para realizar o georreferenciamento do banco, foi utilizada a operação "join" no ArcGIS, tal operação possibilita que as informações tabulares sejam agregadas às informações espaciais. Isto se tornou possível, porque tanto os pontos como cada linha do banco de dados tinham um índice em comum, sendo este, o atributo de junção entre eles;

iv) Criação do banco de dados geotécnicos. A Tabela 1 ilustra uma amostra do banco gerado, obtida a partir da exportação da junção entre os dois dados, ficando, dessa forma, as informações geotécnicas como atributo dos pontos georreferenciados. Relate-se que a criação da base de dados georreferenciados dos dados geotécnicos, possibilita a geração de mapas temáticos referentes à Geotecnia do município de Caucaia, relacionados a outras feições, tais como rodovias e hidrografia por exemplo.

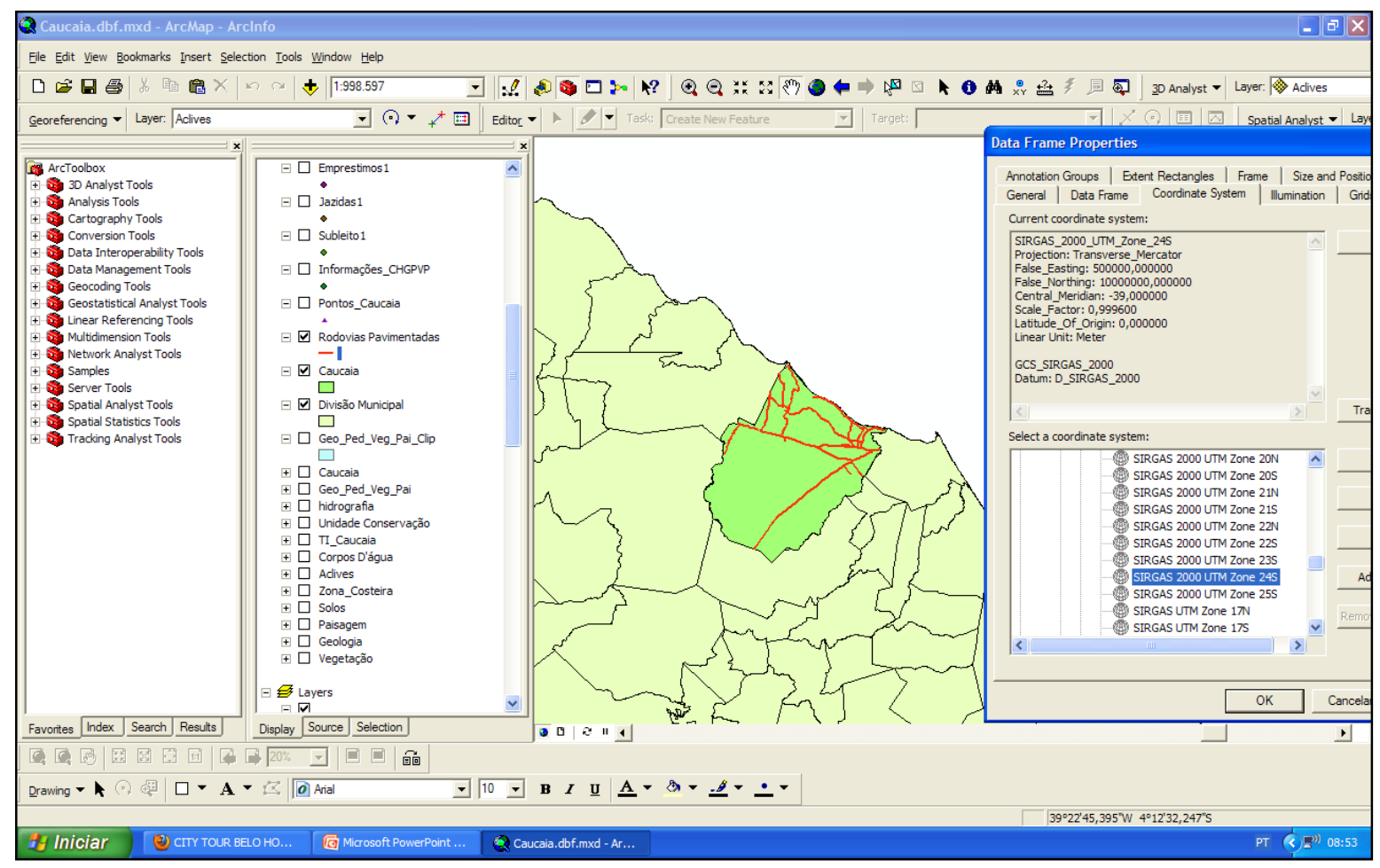

FIGURA 4: Manipulação dos dados vetoriais.

FONTE: Autoria Própria.

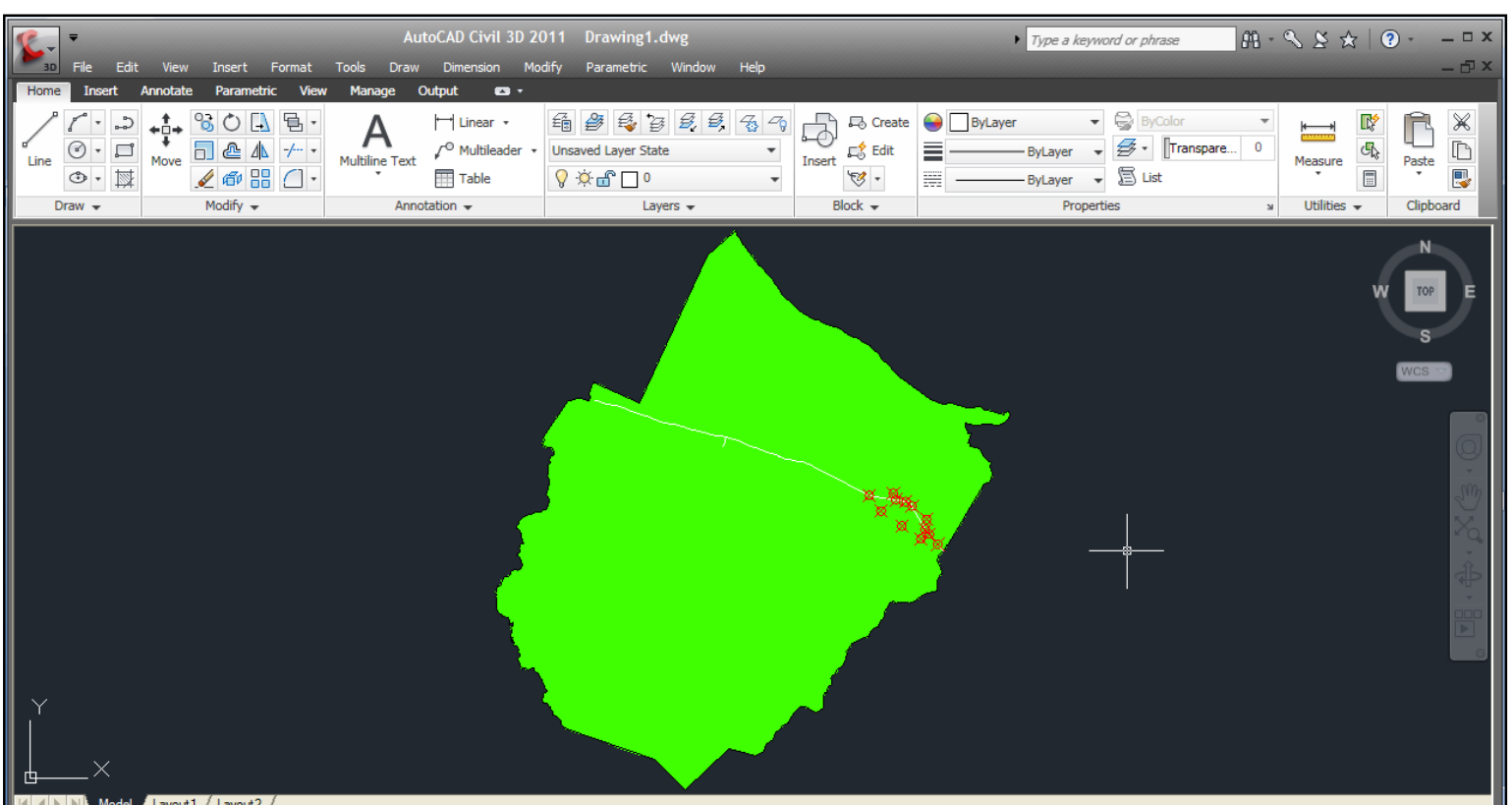

FIGURA 5: Georreferenciamento do pontos geotécnicos. FONTE: Autoria Própria. 


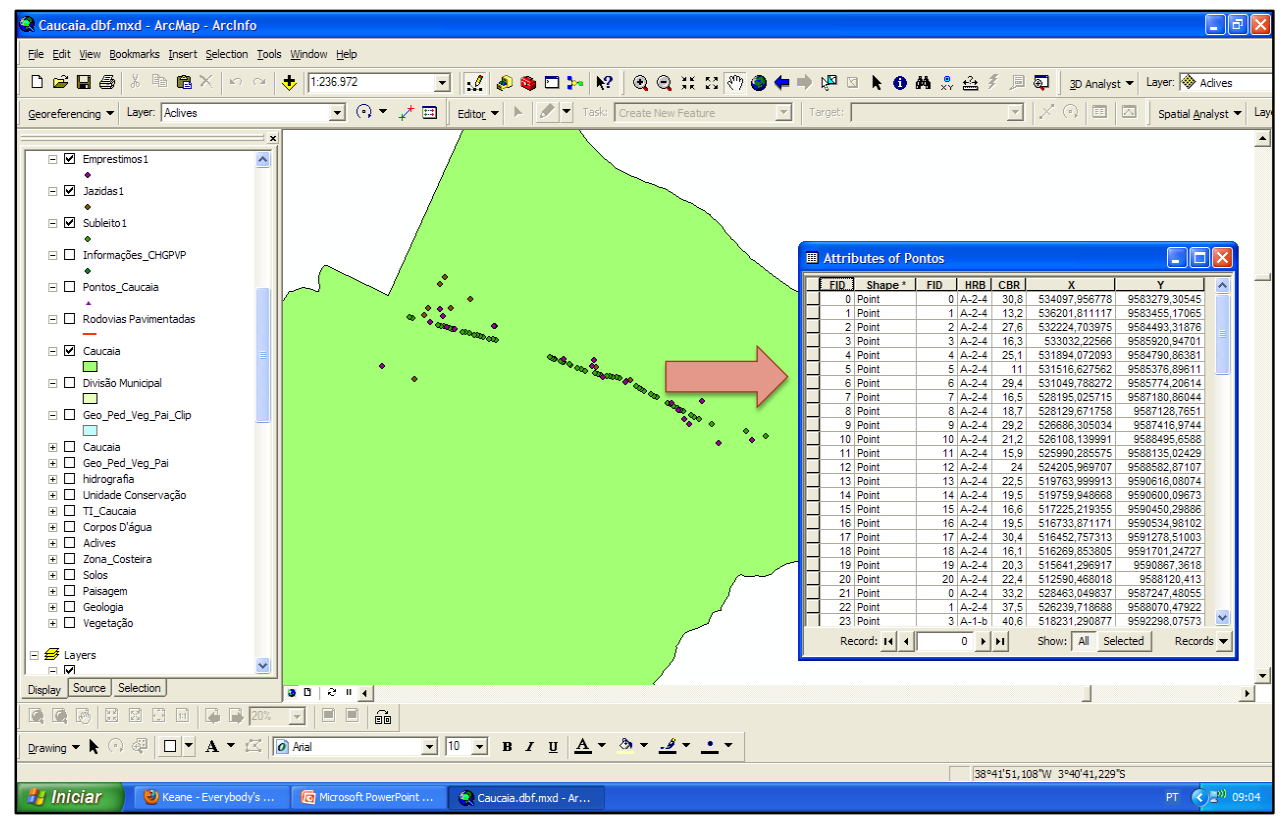

FIGURA 6: Junção do banco de dados geotécnicos à base vetorial. FONTE: Autoria Própria.

TABELA 1: Exemplo de um Banco de Dados Georreferenciado.

\begin{tabular}{ccccc} 
ID & AASHTO & CBR & ESTE & NORTE \\
\hline 1 & A-2-4 & 13,2 & 536201,811 & 9583455,171 \\
22 & A-2-4 & 37,5 & 526239,719 & 9588070,479 \\
67 & A-1-b & 51,0 & 523533,5708 & 9588583,585 \\
68 & A-1-b & 27,0 & 523418,9498 & 9588623,598 \\
38 & A-2-4 & 30,0 & 531485,483 & 9585478,381 \\
45 & A-4 & 4,0 & 529341,568 & 9586568,122 \\
46 & A-6 & 5,0 & 529162,743 & 9586656,052 \\
\hline
\end{tabular}

\subsection{DISCUSSÃO DA APLICAÇÃO DA METODOLOGIA}

Os dados geotécnicos levantados do projeto de duplicação da BR-222, fornecidos pelo DNIT, tornou possível criar um banco de dados espacial, populado com as sondagens $\mathrm{e}$ caracterização dos materiais, perfazendo um total de 89 pontos, com atributos caracterizados por informações geotécnicas direcionadas à pavimentação, tais como CBR e classificação AASHTO. A Figura 7 apresenta o mapa de localização desses pontos no município de Caucaia.

A partir da base de dados criada, foi possível realizar a classificação dos pontos, através da geração de dois mapas temáticos, sendo criadas duas distinções, uma para a classificação AASHTO (Figura 8) e outra para o CBR (Figura 9). O mapa com informações de CBR foi estratificado por faixas de valores.
Analisando-se os mapas temáticos e o banco de dados gerados, é possível fazer uma análise qualitativa e quantitativa dos pontos estudados, de forma a identificar, por exemplo, qual o tipo de material que ocorre com maior frequência na área levantada, bem como suas capacidades de suporte, identificadas por seu CBR, além da visualização de sua distribuição espacial. As Tabelas 2 e 3 e as Figuras 10 e 11 ilustram os percentuais da classificação AASHTO e CBR dos 89 pontos georreferenciados.

A análise dos gráficos das Figuras 11 e 12 possibilita a percepção de que a classe A-2-4 tem predominância, com $70 \%$ dos pontos analisados, e ainda que o valor de CBR é muito variável, porém os valores maiores estão em menor quantidade dentre as amostras. Adicionalmente é possível estratificar os valores de CBR por classe AASHTO, possibilitando uma análise mais detalhada dos dados, como mostra a Tabela 4. 


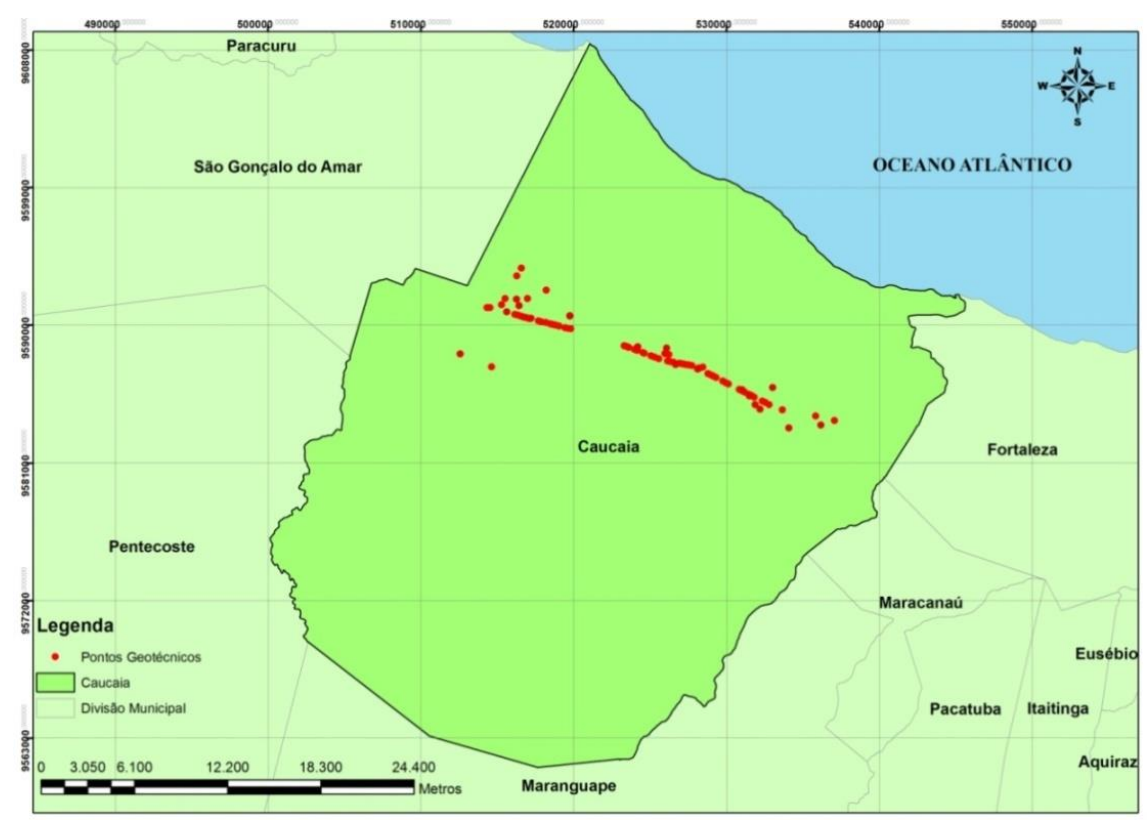

FIGURA 7: Localização dos Pontos Geotécnicos. FONTE: Autoria Própria.

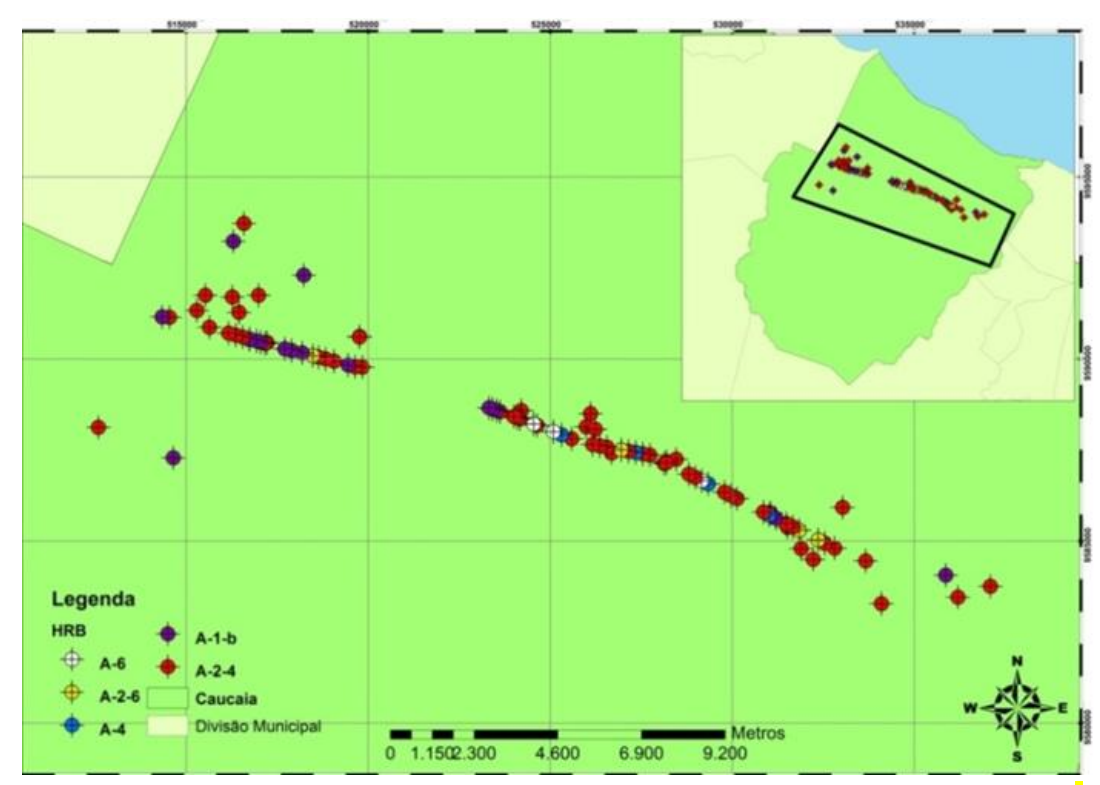

FIGURA 8: Classificação AASHTO dos Pontos. FONTE: Autoria Própria.

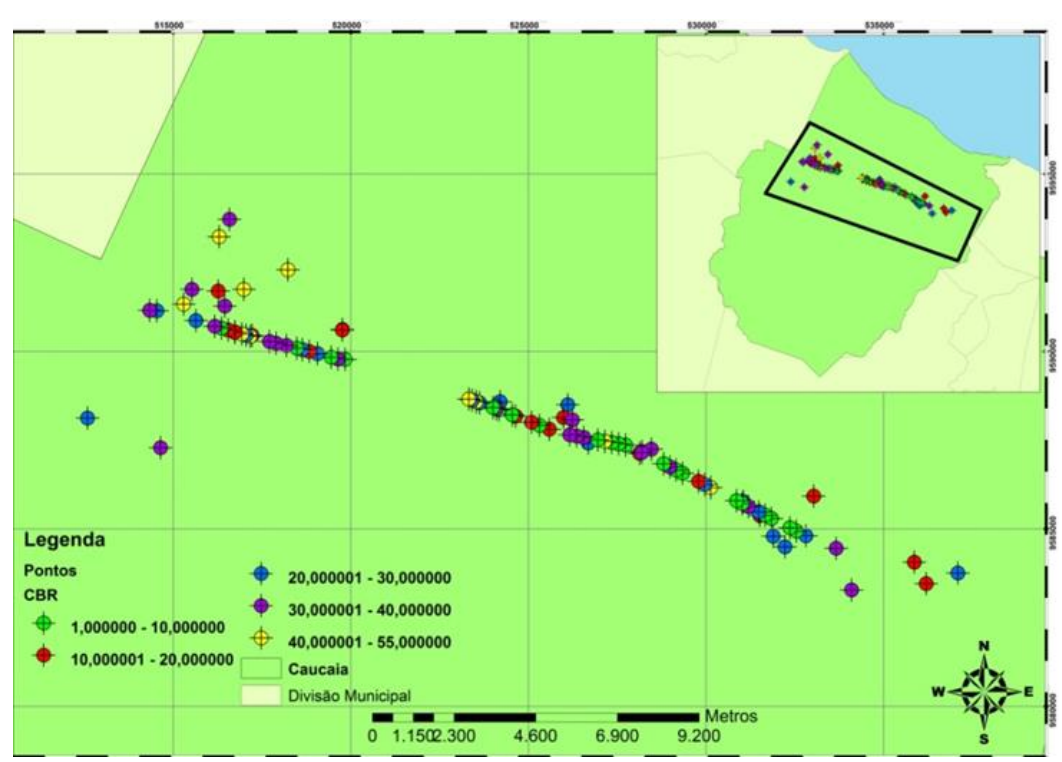

FIGURA 9: Estratificação dos Pontos pelo CBR. FONTE: Autoria Própria. 
TABELA 2: Percentuais de CBR

\section{CBR}

\begin{tabular}{ccc}
\hline $\begin{array}{c}\text { Faixa } \\
\text { (\%) }\end{array}$ & Quantidade & Percentagem (\%) \\
\hline $00-10$ & 21 & $24 \%$ \\
$10-20$ & 18 & $20 \%$ \\
$20-30$ & 19 & $21 \%$ \\
$30-40$ & 22 & $25 \%$ \\
$40-55$ & 9 & $10 \%$ \\
\hline
\end{tabular}

FONTE: Autoria Própria.

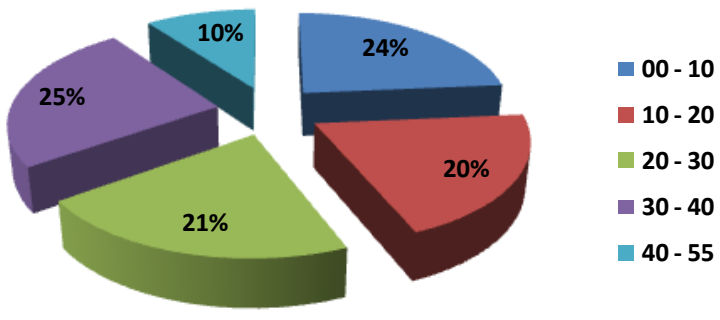

FIGURA 10: Percentuais de CBR. FONTE: Autoria Própria.

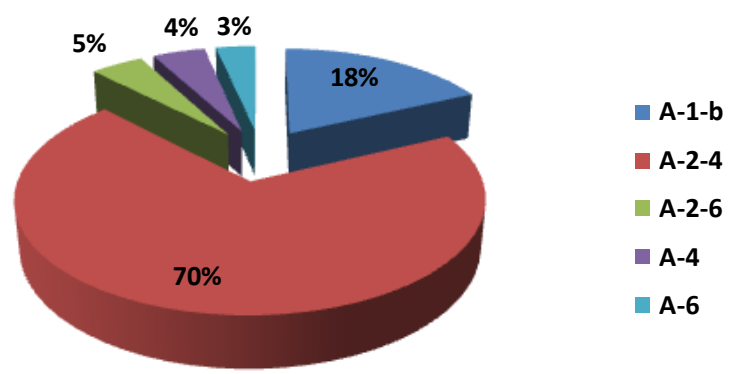

FIGURA 11: Percentuais das classes AASHTO. FONTE: Autoria Própria.

FONTE: Autoria Própria.

\section{AASHTO}

\begin{tabular}{ccc}
\hline Classe & Quantidade & Percentagem (\%) \\
\hline A-1-b & 16 & $18 \%$ \\
A-2-4 & 62 & $70 \%$ \\
A-2-6 & 4 & $4 \%$ \\
A-4 & 4 & $4 \%$ \\
A-6 & 3 & $3 \%$ \\
\hline
\end{tabular}

\section{TABELA 4: CBR em relação às classes AASHTO}

\begin{tabular}{|c|c|c|c|c|c|c|c|c|c|}
\hline \multicolumn{2}{|c|}{$\begin{array}{c}\text { A-2-4 } \\
70 \% \text { do Total }\end{array}$} & \multicolumn{2}{|c|}{$\begin{array}{c}\text { A-1-b } \\
18 \% \text { do Total }\end{array}$} & \multicolumn{2}{|c|}{$\begin{array}{c}\text { A-2-6 } \\
4 \% \text { do Total }\end{array}$} & \multicolumn{2}{|c|}{$\begin{array}{c}\text { A-4 } \\
4 \% \text { do Total }\end{array}$} & \multicolumn{2}{|c|}{$\begin{array}{c}\text { A-6 } \\
3 \% \text { do Total }\end{array}$} \\
\hline CBR & $(\%)_{\text {Parcial }}$ & CBR & $(\%)_{\text {Parcial }}$ & CBR & $(\%)_{\text {Parcial }}$ & CBR & $(\%)_{\text {Parcial }}$ & CBR & $(\%)_{\text {Parcial }}$ \\
\hline $3-13$ & $23 \%$ & $10-19$ & $19 \%$ & --- & --- & --- & --- & --- & --- \\
\hline $13-24$ & $28 \%$ & $19-28$ & $13 \%$ & 1 & $25 \%$ & --- & --- & --- & --- \\
\hline $24-34$ & $28 \%$ & $28-37$ & $31 \%$ & 6 & $25 \%$ & 4 & $25 \%$ & 5 & $33 \%$ \\
\hline $34-44$ & $15 \%$ & $37-46$ & $25 \%$ & 7 & $25 \%$ & 6 & $50 \%$ & 7 & $33 \%$ \\
\hline $44-55$ & $6 \%$ & $46-55$ & $13 \%$ & 10 & $25 \%$ & 7 & $25 \%$ & 14 & $33 \%$ \\
\hline
\end{tabular}

\section{CONCLUSÕES}

Embora neste experimento tenham sido utilizados dados de projetos de apenas uma rodovia, percebe-se que a metodologia proposta pode ser aplicada inserindo-se dados das cinco rodovias existentes no município, o que certamente melhoraria a visualização espacial dos dados geotécnicos da área de estudo. Outra vantagem da metodologia proposta é a organização sistemática e periódica dos dados armazenados nos órgãos rodoviários e empresas de geotecnia que muitas vezes servem somente de arquivo morto.
A organização desses dados pode facilitar a execução de futuros projetos rodoviários, pois se criaria um arquivo espacial do tipo de subleito e materiais ocorrentes de um dado local, bem como dos materiais que já foram empregados em camadas granulares de pavimentos. Essa ação poderia reduzir custos dos projetos geotécnicos rodoviários futuros.

De posse dos resultados obtidos, para o caso do município de Caucaia, verificou-se que é possível sistematizar a criação de um banco de dados georreferenciado, partindo-se de dados 
secundários, tais como estudos e projetos, além de "As Built" de obras rodoviárias. Em adição, demonstrou-se que as ferramentas de Geoprocessamento são essenciais para o emprego do método aqui proposto, dado a sua eficiência e facilidade na manipulação das informações.

Atualmente há um volume muito grande de dados e informações espaciais disponíveis na web de forma gratuita, tanto tabulares quanto em formato de imagens vetoriais e raster, que podem ser usados em diferentes análises e modelagens. No caso da Geotecnia com fins de pavimentação, sugere-se a integração do banco de dados proposto às feições biofísicas e antrópicas para possibilitar a geração de modelos que permitam, por exemplo, a inferência de características geotécnicas, bem como modelos de gerência de pavimentos e estudos de impactos ambientais para construção e manutenção de rodovias em uma dada região.

É importante ressaltar que o projeto da BR-222 não explicita os resultados das jazidas que foram descartadas, o que leva a acreditar que alguns resultados das características dos solos e propriedades possam estar sendo superestimados, pois basearam-se somente naqueles materiais que tinham aplicabilidade em camadas granulares dos pavimentos. Tal problema poderia ser mitigado com a organização das informações em uma base de dados para estudos e projetos rodoviários, como a proposta apresentada nesse trabalho. Os órgãos e pesquisadores poderiam facilmente montar uma base de dados com essas informações, o que facilitaria os trabalhos atuais e futuros a serem executados nas áreas de interesse.

Adicionalmente, o estudo aqui desenvolvido pode servir para organizar e sistematizar os tipos de subleitos que ocorrem numa dada região, facilitando assim, a elaboração de catálogos de dimensionamento de pavimentos mais realistas. Enfim, espera-se que o presente trabalho possa contribuir para elaboração de um futuro mapeamento geotécnico do estado do Ceará com finalidades rodoviárias, facilitando 0 desenvolvimento de novos métodos de dimensionamento que incluam o conceito da mecânica dos pavimentos. Para tanto, torna-se necessário organizar uma base de dados com valores do módulo de resiliência, por exemplo.

Por fim, sugere-se aos órgãos rodoviários que incluam o georreferenciamento dos pontos de sondagem (subleito, jazidas, empréstimos) em suas orientações de estudos geotécnicos, de modo a facilitar a integração dos mesmos a banco de dados espaciais de informações e características geotécnicas.

\section{REFERÊNCIAS BIBLIOGRÁFICAS}

ALMEIDA, A. C. M. (2000) Disponibilização dos Dados Geográficos da Região Metropolitana de Salvador através de uma Rede de Alta Velocidade. Projeto REMA - Salvador.

ARONOFF, S. (1989) Geographic Information Systems: A Management Perspective. WDL Publications, Ottawa, Canadá.

BARROSO, S. H. A. (2002) Estudo dos Solos da Região Metropolitana de Fortaleza para Aplicação na Engenharia Rodoviária. Tese de Doutorado, EESC-USP, Departamento de Transportes, São Carlos, SP.

BURROUGH, P. A. (1986) Principles of Geographical Information Systems for landresources Assessment. Clarendon Press, Oxford, 193p.

CÂMARA, G.; MEDEIROS, C. B.; CASA NOVA, M. A.; HEMERLY, A.; MAGALHÃES, G. (1996) Anatomia de Sistemas de Informação Geográfica. Escola de Computação, SBC.

CÂMARA, G. \& QUEIROZ, G. (2006). Banco de Dados Geográficos - Introdução aos Sistemas de Bancos de Dados - Parte I. Página Web: http://www.dpi.inpe.br/livros/bdados/capitulos.html>. Acesso em: Janeiro de 2016

CHAVES, F.J. (2000). Caracterização Geotécnica de Solos da Formação Barreiras da Região Metropolitana de Fortaleza para Aplicação em Obras Rodoviárias. Dissertação de Mestrado, COPPE/UFRJ, Rio de Janeiro, RJ, Brasil.

DIAS, R. D. (1995) Proposta de Metodologia de Definição de Carta Geotécnica Básica em Regiões Tropicais e Subtropicais. Artigo obtido na Revista IG, v. especial, São Paulo, SP, 1995.

FORTES, L. R. G. M. (1998) Processo de Modelagem de Dados em Sistema de Informação Geográfica. Dissertação de Mestrado, Escola Politécnica, Universidade de São Paulo, 211p. http://www.ipece.ce.gov.br/noticias/85-mais-industriasno-cipp - Acessado em maio de 2011. 
IBGE (2010) Censo Populacional 2010. Rio de Janeiro, RJ.

MCBRATNEY, A. B.; MENDONCA SANTOS, M. L.; MINASNY, B. On digital soil mapping. Geoderma, Amsterdam, v. 117, n. 1-2, p. 3-52, 2003

NOGAMI, J. S., VILLIBOR, D. F. (1981) Uma Nova Classificação de Solos para Finalidades Rodoviárias. In: Simpósio Brasileiro de Solos Tropicais em Engenharia. Rio de Janeiro. Separata.

REEVE, D.E. (2001) Apostila on line. University of Salford. Disponível em: http://www.els.salford.ac.uk/geog/staff/nmt/fungis/hsd /hsd5.htm>. Acessado em maio de 2011.

RIBEIRO, ANTONIO JÚNIOR ALVES; DA SILVA, CARLOS AUGUSTO UCHÔA; DE ARAÚJO BARROSO, SUELLY HELENA. Neural Estimation of Localization and Classification of Soils for Use in Low-Traffic-Volume Roads. Transportation Research Record, v. 2473, p. 98106, 2015.

ROVANI, F. F. M.; VIERA, M. (2016) Vulnerabilidade Natural do Solo de Silveira Martins-RS. Floresta e Ambiente (2016).

SILVA, R. Banco de Dados Geográficos: Uma Análise das Arquiteturas Dual (Spring) e Integrada (Oracle Spatial). Escola Politécnica da USP. 2002. 